\title{
Improvement of earthing systems with backfill materials
}

\begin{abstract}
Long term performance of several backfill materials, which are freely available as industrial wastes or at a low cost in Sri Lanka, have been investigated by taking the earth resistance of deep driven Galvanized Iron (GI) electrodes over a period of 2-3 years. The best performing material, metal oxide powder (a waste product of steel industry), was tested against several commercially available and traditionally used backfill materials. It was found that these industrial wastes reach the level of performance of commercially available backfill materials after several months. It was also found that the percentage of material erosion of GI due to corrosion in the presence of metal oxide powder is less than $1 \%$ after more than two years in contact. Lime and coke breeze also show good performance with respect to corrosion while commercially available natural Bentonite performs the best. Sodium Chloride, a backfill material that is widely used in South Asia, gave highly undesirable outcome; the earth resistance of the relevant electrode fluctuates in a wide range of values and the corrosive effects are unacceptably high. The resistivity and the change of resistivity of each material under dry and wet conditions were measured to find a relation between the earth resistance and the observed parameters. Under dry conditions the resistivity of most of the well performed backfill materials has somewhat higher values, however under wet conditions the resistivity markedly reduces to a low value. This change of resistivity appears to be a characteristic of a good backfill material. However, Sodium Chloride, which possesses such characteristic, should not be used as a backfill material due to a number of drawbacks.
\end{abstract}

